\title{
Weed management in rhubarb (Rheum raponticum L.) in Poland and other countries
}

\section{Ochrona rabarbaru (Rheum raponticum L.) przed chwastami w Polsce i innych krajach}

\author{
Ewa Matyjaszczyk $^{1 *}$, Adam Dobrzański ${ }^{2}$
}

\begin{abstract}
Summary
The issue of weed control in rhubarb in Poland was presented and compared to the other countries. The ecological niche for weeds, floristic structure of weed communities and weed population dynamics in rhubarb plantings depend on different agrobiological factors. In Poland, rhubarb protection against weeds is based mainly on non-chemical methods. In most countries where rhubarb is cultivated in integrated weed control strategies herbicides are authorized and recommended. Depending on the country the active substances used in protection of rhubarb against weeds are: glyphosate, propyzamide, pendimethalin, metamitron, clopyralid and clomazone.
\end{abstract}

Key words: rhubarb; weed management; herbicide; minor crops; plant protection legislation; plant protection products

\section{Streszczenie}

Przedstawiono możliwości ochrony rabarbaru przed chwastami w Polsce i porównano je z innymi krajami. Nisza ekologiczna chwastów, skład florystyczny i dynamika populacji chwastów w uprawie tej rośliny zależy od różnych czynników agrobiologicznych. W Polsce ochrona rabarbaru przed chwastami oparta jest głównie na metodach niechemicznych. W większości krajów, gdzie rabarbar jest uprawiany, w integrowanej ochronie przed chwastami zarejestrowane i zalecane są różne herbicydy. W zależności od kraju do ochrony rabarbaru przed chwastami stosuje się następujące substancje czynne: glifosat, propyzamid, pendimetalinę, metamitron, chlopyralid i chlomazon.

Słowa kluczowe: rabarbar; zwalczanie chwastów; herbicydy; uprawy małoobszarowe; przepisy dotyczące ochrony roślin; środki ochrony roślin

\footnotetext{
Instytut Ochrony Roślin - Państwowy Instytut Badawczy

Władysława Węgorka 20, 60-318 Poznań

${ }^{2}$ Instytut Ogrodnictwa

Konstytucji 3 Maja 1/3, 96-100 Skierniewice

Wyższa Szkoła Humanistyczno-Ekonomiczna

Mazowiecka 1B, 96-100 Skierniewice

*corresponding author: e.matyjaszczyk@iorpib.poznan.pl
} 


\section{Wstęp / Introduction}

Rabarbar zaliczany jest do wieloletnich upraw małoobszarowych (Rozporządzenie 2013). Plantację użytkuje się przez okres $10-15$ lat poza zmianowaniem. Jest on uprawiany nie tylko do bezpośredniego spożycia, ale również jako surowiec dla przemysłu, z przeznaczeniem do naturalnego zakwaszania przetworów owocowo-warzywnych i kandyzowania, ma też zastosowanie w farmacji. Na dużych, produkcyjnych plantacjach rabarbaru, jego uprawa jest utrudniona bez zabezpieczenia środkami ochrony roślin, z herbicydami włącznie. Dokładna powierzchnia uprawy rabarbaru w Polsce nie jest znana, ale prawdopodobnie nie przekracza ona 1000 ha.

Obecnie w Polsce, podobnie jak w innych państwach członkowskich Unii Europejskiej, obowiązkowe jest stosowanie integrowanej ochrony roślin. Wymaga ona kompleksowego podejścia do ochrony, w tym zapobiegania występowaniu organizmów szkodliwych lub minimalizowaniu ich negatywnego wpływu na rośliny uprawne. Integrowana ochrona roślin zaleca również stosowanie metod niechemicznych. Metody prewencyjne oraz niechemiczne dobrze sprawdzają się w ochronie rabarbaru przed chwastami i zostały omówione w niniejszej publikacji. Nie zawsze jednak są wystarczające.

\section{Problem chwastów na plantacjach rabarbaru Problem of weeds in rhubarb}

Nisza ekologiczna chwastów, skład florystyczny i dynamika populacji chwastów zależy od różnych czynników agrobiologicznych. W integrowanej ochronie przed chwastami system wspomagania decyzji o ich zwalczaniu zaleca się opierać o monitoring polegający na dobrym rozpoznaniu składu gatunkowego flory segetalnej w zależności od rodzaju gleby i innych uwarunkowań agroekologicznych (Rola i wsp. 1999; Domaradzki i wsp. 2003; Rydahl i Boejer 2007). Istotna jest też znajomość dynamiki pojawiania się poszczególnych taksonów w czasie każdego sezonu wegetacyjnego $\mathrm{i}$ w kolejnych latach uprawy. Rabarbar tworzy dużą masę liści, która dobrze zakrywa glebę. Jednak w stosunkowo szerokich międzyrzędziach mogą pojawiać się chwasty, zwłaszcza w pierwszym roku uprawy. Trudno jest określić, jakie szkody w uprawie rabarbaru może powodować zachwaszczenie, gdyż brak jest polskich badań na ten temat, a w dostępnej literaturze też nie można znaleźć takich informacji. Roślina ta jest zapewne mniej wrażliwa na konkurencję ze strony chwastów niż większość warzyw jednorocznych, szczególnie uprawianych z siewu. Niemniej jednak obecność chwastów na plantacji rabarbaru nie jest pożądana. Z chwastów na rabarbar mogą przenosić się niektóre szkodniki. W zachwaszczonych plantacjach panują też warunki sprzyjające rozwojowi chorób. Nie można wykluczyć, że organizmy chorobotwórcze z rdestów i szczawiów należących do tej samej rodziny botanicznej mogą się przenosić na rabarbar. Dobrze prowadzona plantacja powinna być utrzymywana w stanie wolnym od chwastów przez cały okres jej użytkowania.

W Polsce przeprowadzono wiele obserwacji nad rozmieszczeniem i występowaniem różnych gatunków chwastów w wielkoobszarowych uprawach roślin rolniczych (Kaczmarek i wsp. 2013; Rola i Rola 2013), a także roślin warzywnych, głównie w uprawach jednorocznych (Dobrzański 1999, 2013; Siciński 2000; Urban i Dobrzański 2011). Brak jednak udokumentowanych badań wynikających z klasycznych obserwacji fitosocjologicznych flory segetalnej spotykanej na plantacjach rabarbaru. Znaleźć można głównie opisy stanu i stopnia zachwaszczenia, na podstawie obserwacji plantacji produkcyjnych, w zaleceniach przeznaczonych dla praktyki, niepoparte wynikami badań (Adamicki i wsp. 2003; Dobrzański 2003a). Jeżeli stanowisko pod uprawę rabarbaru jest przygotowane starannie i karpy tej rośliny posadzono jesienią na polu wolnym od perzu (Elymus repens) i innych chwastów wieloletnich, to wczesną wiosną już w czasie ruszenia wegetacji, przed ukazaniem się pąków liściowych rabarbaru pojawiają się różne gatunki chwastów, przeważnie dwuliściennych. Są to gatunki, dla których minimalna temperatura kiełkowania wynosi poniżej $3-4^{\circ} \mathrm{C}$ (np. Capsella bursa-pastoris, Thlaspi arvense, Stellaria media, Senecio vulgaris, taksony z rodzajów Lamium ssp., Anthemis ssp., Matricaria ssp.). Niektóre gatunki, np. S. media i $S$. vulgaris mogą pojawiać się nawet w czasie łagodnej zimy i bardzo wcześnie wiosną. Chwasty wschodzące jesienią mogą być uszkadzane przez mróz, ale po wiosennym ociepleniu natychmiast się regenerują. Zanim gleba po zimie przeschnie, do poziomu umożliwiającego przeprowadzenie na polu zabiegów mechanicznych i ręcznego pielenia, zdążą się silnie ukorzenić i stają się trudne do usunięcia. Rabarbarowi sadzonemu wiosną, już od początku wegetacji zazwyczaj towarzyszą, oprócz wymienionych gatunków, także Chenopodium album, Fumaria officinalis, Sonchus arvensis, Polygonum ssp., Fallopia convolvulus, Aethusa cynapium, Geranium pusillum, Urtica urens, Euphorbia helioscopia, Veronica ssp. Większość z nich cechuje się „szeroką amplitudą ekologiczną”, czyli mogą wschodzić przez cały okres wegetacji (Lauer 1953; Markow 1978; Dobrzański 2008). Powszechnie spotykana w uprawach warzyw Galinsoga parviflora zazwyczaj pojawia się później, około połowy kwietnia i może silnie zachwaszczać plantację, gdy wiosną temperatura gleby przekracza 6- $8^{\circ} \mathrm{C}$, a w kwietniu i na początku maja są dni $\mathrm{z}$ temperaturą około $20^{\circ} \mathrm{C}$. Jest to gatunek światłolubny i stanowi większe zagrożenie $\mathrm{w}$ pierwszym i drugim roku po założeniu plantacji, gdy rabarbar słabo zakrywa liśćmi powierzchnię gleby w międzyrzędziach. W dalszych latach, gdy rośliny rabarbaru silnie się rozrosną chwast ten może nie mieć większego znaczenia. W tym czasie mogą też zachwaszczać rabarbar inne ciepłolubne gatunki, mianowicie Amranthus retroflexus i Echinochloa crusgalli. Zachwaszczenie gatunkami krótkotrwałymi może występować też w następnych latach użytkowania plantacji. W miarę upływu lat zmienia się skład florystyczny zachwaszczenia - wzrasta zagrożenie perzem (E. repens) i wieloletnimi gatunkami dwuliściennymi. Nawet na polu, gdzie starannie zlikwidowano perz przed założeniem plantacji, zaczyna on pojawiać się przeważnie już w 4-5 roku od jej założenia, a czasem wcześniej. Rozłogi perzu charakteryzują się silną żywotnością - pocięte na kawałki, podczas mechanicznej uprawy prowadzonej w między- 
rzędziach, wydają nowe rośliny. Nie usunięcie w porę nawet pojedynczych roślin perzu może doprowadzić do jego masowego rozmnożenia się i opanowania całej plantacji. Zdarza się to szczególnie na plantacjach zakładanych na lżejszych glebach, o małej pojemności wodnej i słabiej nawożonych, gdzie powierzchnia gleby jest słabiej zakryta przez liście rabarbaru. Po kilku latach użytkowania plantacji mogą się pojawić gatunki wieloletnie o nasionach $\mathrm{z}$ puchem kielichowym, przenoszone przez wiatr na duże odległości - Taraxacum officinalis, Cirsium arvense, $S$. arvensis. Obecność perzu i chwastów wieloletnich może znacznie skrócić okres użytkowania plantacji.

\section{Metody zapobiegające zachwaszczeniu stosowane przed założeniem plantacji rabarbaru Prevention methods of weed control, used before rhubarb planting}

W regulowaniu zachwaszczenia na plantacji rabarbaru duże znaczenie ma stworzenie warunków zwiększających konkurencyjność tej rośliny w stosunku do chwastów. Należą do nich: odpowiednie zagęszczenie roślin (rozstawa rzędów i odległości w rzędzie), aby w pełni wegetacji zakrywały one liśćmi całą powierzchnię, co ogranicza rozrastanie się chwastów oraz właściwy poziom nawożenia i zaopatrzenia roślin w wodę zapewniający tworzenie dużych liści rabarbaru (Adamicki i wsp. 2003).

W Polsce nie można, zgodnie $\mathrm{z}$ prawem, stosować herbicydów w rabarbarze w czasie jego wegetacji. Dlatego należy starać się maksymalnie odchwaścić pole w okresie przed założeniem plantacji, a także unikać jej lokalizacji na terenach zachwaszczonych perzem oraz wieloletnimi chwastami dwuliściennymi. Zachwaszczenie zmniejszają zabiegi uprawowe w okresie letnio-jesiennym, po zbiorze przedplonu poprzedzającego założenie plantacji zakończone głęboką orką z pogłębiaczem. Można je uzupełnić herbicydami zawierającymi glifosat (w roku 2015 w Polsce było zarejestrowanych ponad 70 takich środków). Wszystkie preparaty zawierające glifosat mają działanie nieselektywne i stosuje się je podobnie. Różnią się jednak zakresem zalecanych dawek, zależnie od zawartości substancji czynnej. W odróżnieniu od zaleceń sprzed kilku lat, obecnie, niezależnie od dawki i terminu stosowania, glifosatem można wykonać tylko jeden zabieg w sezonie wegetacyjnym. Nie można go powtórzyć, nawet gdy po wcześnie zebranym przedplonie, przed jesiennym terminem sadzenia (koniec września - początek października) chwasty zdążą odrosnąć. Sadzenie karp w terminie jesiennym nie powinno być wcześniejsze niż po 7-10 dniach od użycia glifosatu, gdy widać wyraźne objawy zamierania chwastów. Karpy posadzone wcześniej mogą zostać uszkodzone przez herbicyd. W przypadku przygotowywania pola do sadzenia karp wczesną wiosną, gdy w okresie letnio-jesiennym stosowano glifosat i wykonano głęboką orkę przedzimową, późną jesienią przed wystąpieniem mrozów wschodzą chwasty zimujące i ozime, które w fazie rozetek mogą przetrwać do wiosny. Także wiele gatunków chwastów rozpoczyna kiełkowanie bardzo wcześnie wiosną, zanim stan uwilgotnienia gleby umożliwi rozpoczęcie mechanicznej uprawy przed sadzeniem karp. Trzeba jednak możliwie wcześnie glebę uprawić, aby nie dopuścić do rozrośnięcia się chwastów, które zimę przetrzymały lub skiełkowały wiosną (Dobrzański 2008).

\section{Niechemiczne ograniczanie zachwaszczenia po założeniu plantacji / Non-chemical weed control after the establishment of plantation}

Szeroka rozstawa rzędów $(135-150 \mathrm{~cm})$, w jakiej rabarbar jest uprawiany pozwala na mechaniczne zwalczanie chwastów. Jest ono konieczne zwłaszcza w pierwszym roku uprawy, kiedy liście rabarbaru nie zacieniają jeszcze całej powierzchni między roślinami. Zazwyczaj trzeba wykonać 3, czasem 4 mechaniczne uprawki międzyrzędowe połączone $\mathrm{z}$ ręcznym usuwaniem chwastów znajdujących się między odległymi o około $100 \mathrm{~cm}$ roślinami w rzędzie.

Do ograniczania konkurencji chwastów można wykorzystać ściółkowanie czarną folią lub czarną agrowłókniną nieprzepuszczającą światła. Rzędy rabarbaru nakrywa się wiosną pasami folii lub włókniny o szerokości 100-150 cm, brzegi przysypuje się ziemią, a nad wychodzącymi z gleby pąkami liściowymi wycina się otwory lub przecina się ściółkę „na krzyż”, aby umożliwić wschody rabarbaru. Między pasami ściółki chwasty można zwalczać mechanicznie. Ściółkować można też podczas zakładania plantacji rozkładając folię lub włókninę przed sadzeniem karp. Można też stosować ściółki organiczne (rozdrobniona słoma wolna od nasion chwastów, kora i inne) wykładane w międzyrzędziach. Żeby zapobiec zachwaszczeniu warstwa ściółki powinna mieć co najmniej $10 \mathrm{~cm}$ grubości (Creager 1989; Adamicki i wsp. 2003; Dobrzański 2003a).

Właściwości ograniczające zachwaszczenie ma cyjanamid wapnia (Fajkowska i Kozaczenko 1955; Rondomański i Dobrzański 1974; Koch i Hurle 1978; Börner 1995). Nazywany popularnie azotniakiem - cyjanamid wapnia, jest w Polsce, podobnie jak w innych krajach Unii Europejskiej zarejestrowany nie jako herbicyd, lecz jako nawóz o nazwie handlowej Perlka. Od dawna był on polecany w różnych uprawach warzyw, ze względu na to, że poza działaniem nawozowym, niszczy kiełkujące blisko powierzchni nasiona chwastów (Domańska i Kozaczenko 1969). Chociaż brakuje polskich badań nad jego przydatnością do nawożenia rabarbaru, to jest on stosowany w praktyce, w dawce 400-500 kg/ha, bardzo wcześnie wiosną przed ruszeniem wegetacji na wilgotną glebę. Cyjanamid wapnia zawarty w nawozie Perlka zmniejsza zachwaszczenie gatunkami jednorocznymi w okresie ich kiełkowania i wschodów. Jeżeli po zastosowaniu tego nawozu powierzchnia gleby jest przesuszona, to wskazane jest bardzo płytkie mechaniczne jej wzruszenie w międzyrzędziach. Chwastobójcze działanie nawozu Perlka jest krótkotrwałe. Gdy po jego użyciu chwasty nie wschodzą, lepiej zrezygnować $\mathrm{z}$ uprawki międzyrzędowej lub maksymalnie ją opóźnić. Wzruszenie gleby przyspiesza wschody chwastów, zwłaszcza ciepłolubnych, głównie żółtlicy drobnokwiatowej i owłosionej ( $G$. parviflora i G. ciliata). 


\section{Możliwości chemicznej ochrony rabarbaru w Polsce / Possibilities of chemical protection of rhubarb in Poland}

Ochrona przed chwastami rabarbaru uprawianego na dużych plantacjach bez stosowania środków chemicznych nie zawsze jest wystarczająca. We wszystkich krajach, gdzie jego produkcja jest prowadzona na skalę towarową, herbicydy są zalecane i wykorzystywane w praktyce. Tak było też w Polsce do roku 2007. Wówczas, podobnie jak w innych krajach, polecano symazynę w formie środków Azotop 50 WG i Gesatop 50 WP na podstawie badań prowadzonych w latach sześćdziesiątych ubiegłego wieku (Chroboczek i Dobrzański 1970; Dobrzański 2003b). Po wprowadzeniu zakazu stosowania symazyny na obszarze Unii Europejskiej plantatorzy rabarbaru w naszym kraju nie mogą używać herbicydów.

Aby zarejestrować środek ochrony roślin, w tym herbicyd i zezwolić na jego stosowanie w określonej uprawie niezbędne są odpowiednie badania. Ze względu na mały areał uprawy, firmy fitofarmaceutyczne nie wykazuja zainteresowania prowadzeniem badań umożliwiających rejestrację herbicydów dla rabarbaru. Takich badań nie podjęła się też żadna polska placówka badawcza na przestrzeni ostatnich 50 lat. W efekcie tego polscy producenci rabarbaru nie mają legalnej możliwości jego chemicznej ochrony przed chwastami.

\section{Jak jest w innych krajach? / How it is in other countries?}

Analizę możliwości ochrony rabarbaru przed chwastami przeprowadzono w oparciu o zapisy podane w etykietach-instrukcjach obowiązujących w końcu roku 2014 do maja 2015 (Ctgb. Pesticides database 2015; Extension of Authorisation for minor use in the UK 2015; Pflanzenschutzmittel-Verzeichnis 2015) oraz zalecenia na rok 2014 i 2015 przyjęte w różnych krajach. Korzystano też $\mathrm{z}$ informacji podanych $\mathrm{w}$ wyszukiwarkach środków, znajdujących się na stronach internetowych organów odpowiedzialnych za rejestrację (Approved pesticides 2015) oraz z europejskiej bazy danych o pestycydach (EU Pesticides database 2015) i z bazy Europejskej i Śródziemnomorskiej Organizacji Ochrony Roślin (EPPO) dotyczącej rejestracji środków w Europie (Databases on registered plant protection products in Europe 2015).

W poszczególnych krajach różny jest asortyment zalecanych środków. Prawie we wszystkich krajach europejskich, a także w USA (Peachey 2015), w rabarbarze zalecane są środki, których substancją czynną jest propyzamid. Związek ten zaleca się stosować po zakończeniu zbiorów, późna jesienią po przymrozkach, kiedy rośliny przejdą w stan spoczynku lub bardzo wczesną wiosną przed ruszeniem wegetacji, zanim ukażą się pączki. Nie zaleca się go stosować w pierwszym roku po założeniu plantacji. Można korzystać prawie wszędzie $\mathrm{z}$ glifosatu przed wschodami rabarbaru zanim ukażą się liście lub po wschodach tylko w międzyrzędziach. Na przykład w Niemczech według stanu na maj 2015 r. zaleca się 30 herbicydów, w tym 12 zawierających glifosat, 7 pro- pyzamid, 8 kwas pelargonowy oraz po jednym zawierającym: pendimetalinę, chlopyralid i izoksaben. W Wielkiej Brytanii do ochrony rabarbaru zaleca się ponad 50 różnych środków (w tym 23 zawierające propyzamid pod różnymi nazwami) i na tzw. ,zastosowanie małoobszarowe" - na własną odpowiedzialność można aplikować: metamitron, pedimetalinę, chlomazon i propachizafop. W Irlandii można stosować 5 herbicydów: 2 zawierające pendimetalinę i 3 propyzamid. W Holandii, Belgii i Luksemburgu zaleca się kilka preparatów zawierających propyzamid (z zastrzeżeniem - tylko 1 raz na 12 miesięcy) oraz chlomazon.

W Kanadzie w prowincji Ontario (Guide to weed control 2014-2015) plantacje można odchwaszczać mezotrionem stosowanym przed ruszeniem wegetacji, gdy rabarbar jest $\mathrm{w}$ stanie spoczynku przed ukazaniem się pąków liściowych - 42, a w USA - 21 dni przed zbiorem (Peachey 2015). W USA zalecane są też przed wschodami rabarbaru i chwastów, takie substancje czynne, jak: napropamid, metolachlor-S, linuron, halosulfuron i mezotrion. Po wschodach tylko międzyrzędzia można opryskiwać karfentrazonem (Peachey 2015). W Unii Europejskiej substancje te nie sa dopuszczone do stosowania w rabarbarze, aczkolwiek w Polsce linuron był zalecany w latach sześćdziesiątych ubiegłego wieku (Domańska i Kozaczenko 1969).

Chlomazon jest polecany przed wschodami rabarbaru zanim jego pąki liściowe ukażą się nad powierzchnią gleby oraz wcześnie po wschodach tylko w międzyrzędziach. W Wielkiej Brytanii preparaty zawierające metamitron poleca się stosować nie później niż do 28 dni przed pierwszym zbiorem rabarbaru. Takie środki można u nas stosować tylko $\mathrm{w}$ buraku cukrowym, niektóre $\mathrm{z}$ nich też w ćwikłowym (np. Goltix 700 SC). Pendimetalina, głównie $\mathrm{w}$ formie środka Stomp Aqua $455 \mathrm{CS}$ (dopuszczona w naszym kraju w uprawie cebuli, cebuli z siewu, marchwi i grochu) jest zalecana wiosną, przed wznowieniem wegetacji, na glebę wolną od chwastów. Według informacji otrzymanej od producenta tego środka podejmowne są u nas starania o uzyskanie zezwolenia na jego aplikację między innymi w rabarbarze, chrzanie i szparagu, bez badań wykonywanych w Polsce na ,zastosowanie małoobszarowe", co oznacza, że odpowiedzialność za skuteczność działania i fitotoksyczność środka ponosi wyłącznie użytkownik.

Oczywiste jest, że jednym herbicydem nie można ograniczyć występowania wszystkich gatunków chwastów, które w rabarbarze mogą wystąpić, chociażby dlatego, że na skutek wielokrotnego jego stosowania chwasty mogą się uodpornić. Żeby temu zapobiec konieczne jest przemienne stosowanie różnych substancji czynnych (Adamczewski 2014), zwłaszcza w uprawie warzyw wieloletnich.

\section{Podsumowanie i wnioski / Summation and conclusions}

Stosowanie niechemicznych metod ochrony rabarbaru przed chwastami jest skuteczne, ale nie zawsze wystarczające. Sytuacja, kiedy producenci z innych krajów korzystają z legalnie dostępnych środków chemicznych, 
a w Polsce nie mają dostępu do chemicznej ochrony stawia polskich rolników na niekorzystnej pozycji i nie sprzyja równorzędnej konkurencji na wspólnym rynku.

Jakie działania powinny być podjęte, aby poprawić obecną sytuację i umożliwić integrowaną uprawę rabarbaru na dużych plantacjach? Przepisy Unii Europejskiej umożliwiają ocenę strefową nowych środków ochrony roślin. Obniża ona koszty rejestracji ponoszone przez producentów, ponieważ nie jest już konieczne, aby badania rejestracyjne wykonywać w każdym państwie członkowskim $\mathrm{z}$ osobna. Polska należy do tej samej strefy co Holandia, Niemcy i Wielka Brytania. Jednak w przypadku oceny strefowej z wnioskiem powinien wystąpić producent środka ochrony roślin, a większość producentów nie kwapi się do działań na rzecz upraw małoobszarowych.

Istnieje także możliwość rozszerzenia rejestracji środka ochrony roślin (na mocy zezwolenia Ministra Rolnictwa i Rozwoju Wsi) na rośliny małoobszarowe nieobjęte reje- stracją, a nie ulega wątpliwości, że rabarbar należy do upraw małoobszarowych (Rozporządzenie 2013). W artykułach wcześniej opublikowanych przedstawiono propozycję różnych działań, jakie powinny być podejmowane w przypadku upraw małoobszarowych, aby poprawić dostęp do chemicznej ochrony (Matyjaszczyk 2013; Matyjaszczyk i Dobrzański 2013). Zgodnie z unijnym Rozporządzeniem 1107/2009 (2009), z wnioskiem o wydanie zezwolenia na stosowanie środka w uprawach małoobszarowych mogą występować instytucje państwowe, placówki naukowe i społeczno-zawodowe organizacje rolników, izby rolnicze, producenci środków ochrony roślin, a nawet każdy plantator zajmujący się uprawą roślin.

Należy podkreślić, że problem braku środków chemicznych dla upraw małoobszarowych, w tym rabarbaru nie rozwiąże się sam i wymaga współdziałania producentów agrochemikaliów, urzędów odpowiedzialnych za rejestrację, ale także producentów rolnych.

\section{Literatura / References}

Adamczewski K. 2014. Zapobieganie powstawaniu odporności. s. 182-190. W: „Odporność chwastów na herbicydy.” PWN, Warszawa, 276 ss.

Adamicki F., Dobrzański A., Robak J., Rogowska M., Stępowska A., Szwejda J. 2003. Integrowana uprawa rabarbaru ogrodowego. Instytut Warzywnictwa, Skierniewice, 44 ss.

Approved pesticides for use on vegetable crops 2015 (S. Alexander, ed.). Teagasc. www.teagasc.ie/publications [Accessed: 20.05.2015].

Börner H .1995. Unkrtautbekäpfung. Gustav Fisher Verlag, Jena I, 315 pp.

Chroboczek E., Dobrzański A. 1970. Ocena kilku herbicydów do odchwaszczania grochu, cebuli, buraka ćwikłowego i rabarbaru. Zeszyty Naukowe Szkoły Gospodarstwa Wiejskiego, Ogrodnictwo 6: 7-29.

Creager R.A. 1989. Evaluation of various methods of weed control for increasing rhubarb yields. Crop Protection 8 (6): $443-446$.

Ctgb. Pesticides database. 2015. http://www.ctb-wageningen.nl/ [Accessed : 20.05.2015].

Databases on registered plant protection products in Europe. 2015. http://www.eppo.int/PPPRODUCTS/information/information ppp.html [Accessed: 20.05.2015].

Dobrzański A. 1999. Chwasty w uprawach warzywnych - aktualne problemy i zagrożenia. s. 11-14. W: Przenikanie gatunków ruderalnych z siedlisk sadowniczych i parkowych do zbiorowisk segetalnych, upraw warzywniczych i rolniczych. XXIII Krajowa Konferencja Naukowa z cyklu: Rejonizacja chwastów segetalnych w Polsce. Instytut Warzywnictwa, Skierniewice, 15-16 lipiec 1999,68 ss.

Dobrzański A. 2003a. Ochrona rabarbaru przed chwastami. Cz. 1 Metody agrotechniczne. Hasło Ogrodnicze 9: 94-96.

Dobrzański A. 2003b. Ochrona rabarbaru przed chwastami. Cz. 2 Metody chemiczne. Hasło Ogrodnicze 10, s. 72.

Dobrzański A. 2008. Rola chwastów zimujących ozimych w agrofitocenozach upraw warzyw. Zeszyty Naukowe Wydziału Ogrodniczego, Wyższa Szkoła Ekonomiczno-Humanistyczna w Skierniewicach, Zeszyt 8: 85-100.

Dobrzański A. 2013. Biologiczne i agrotechniczne aspekty regulowania zachwaszczenia. s. 27-54. W: „Współczesna inżynieria rolnicza - osiągnięcia i nowe wyzwania.” Tom III (R. Hołownicki, M. Kuboń, red.). PTIR, Kraków, 443 ss.

Domańska H., Kozaczenko H. 1969. Herbicydy w warzywnictwie. PWRiL, Warszawa, 123 ss.

Domaradzki K., Praczyk T., Matysiak K. 2003. Prototype of Polish version of Decision Suport System for weeds. DIAS Report Plant Production 96, p. 175.

EU Pesticides database. 2015. ec.europa.eu/food/plant/pesticides/pesticides_database/index_en.html [Accessed: 23.04.2015].

Extension of Authorization for minor use in the UK. 2015. https://secure.pesticides.gov.uk/offlabels/ [Accessed: 20.05.2015]

Fajkowska H., Kozaczenko H. 1955. Wyniki dalszych doświadczeń nad wartością azotniaku w zwalczaniu chwastów w roślinach warzywnych. Biuletyn Warzywniczy, Tom 3: 73-79.

Guide to weed control 2014-2015. Publication 75. Ministry of Agriculture and Food. Ministry of Rural Affairs, Canada, 429 pp.

Kaczmarek S., Matysiak K., Adamczewski K. 2013. Cereal mixtures - an effective weed management tool. Journal of Plant Protection Research 53 (4): 364-374

Koch W., Hurle K. 1978. Grundlgen der Unkrtautbekäpfung. Verlag Eugen Ulmer, 205 pp.

Lauer E. 1953. Über die Keimtemperatur von Ackerunkräutern und deren Einfluß auf die Zusammensetzung von Unkrautgesellschaften. Flora 140: 551-595.

Markow M. 1978. Agrofitocenologia nauka o zbiorowiskach roślinnych. PWRiL, Warszawa, 267 ss.

Matyjaszczyk E. 2013. Dostępność środków ochrony roślin dla upraw małoobszarowych i jej konsekwencje w świetle struktury rolnej w Polsce. Roczniki Naukowe Stowarzyszenia Ekonomistów Rolnictwa i Agrobiznesu XV (2): 215-220.

Matyjaszczyk E., Dobrzański A. 2013. Ochrona przed chwastami roślin ozdobnych uprawianych z cebul i bulw w Polsce i w innych krajach Unii Europejskiej. [Weed management of bulb flowers in Poland and other European Union countries]. Progress in Plant Protection/Postepy w Ochronie Roślin 53 (2): 282-290.

Peachey E. 2015. PNW Weed Management Handbook. Vegetable Crops N-2. http://pnwhandbooks.org/ [Accessed: 20.05.2015].

Pflanzenschutzmittel-Verzeichnis 2015. Teil 2.Gemüsebau-Obstbau-Zierpflanzenbau. Bundesamt für Verbraucherschutz und Lebensmittelsicherheit. Braunschweig, 414 pp. 
Rola J., Rola H. 2013. 40 lat zespołowych badań nad biologią i rejonizacją chwastów segetalnych w Polsce (1971-2011). IUNG, Puławy, 331 ss.

Rola H., Rola J., Zaliwski A. 1999. Monitoring stanu stopnia zachwaszczenia upraw rolniczych w Polsce. [Monitoring of weed infestation of field crop in Poland]. Progress in Plant Protection/Postępy w Ochronie Roślin 39 (1): $289-297$.

Rondomański W., Dobrzański A. 1974. Weed control action of calcium cyanamide used as a soil disinfectant in horticulture. Proceedings of XIX International Horticultural Congress. Warszawa, 11-18.09.1974, Vol. 1A, 235 pp.

Rozporządzenie Ministra Rolnictwa i Rozwoju Wsi z dnia 22 maja 2013 r. w sprawie zastosowań małoobszarowych środka ochrony roślin. (Dz.U. 2013, poz. 659).

Rozporządzenie Parlamentu Europejskiego i Rady (WE) NR 1107/2009 z dnia 21 października 2009 r. dotyczące wprowadzania do obrotu środków ochrony roślin i uchylające dyrektywy Rady 79/117/EWG i 91/414/EWG. (Dz.U. UE 2009, L 309/1).

Rydahl P., Boejer O.Q. 2007. A Danish decision support system for weed control. p. 135. In: 14th European Weed Research Society Symposium. Norway, Hamar, 17-21.06.2002, 238 pp.

Siciński J. 2000. Zbiorowiska chwastów upraw warzywnych w rejonie Łęczycy. Acta Universitatis Lodziensis, Folia Biologica et Oecologica 15: 67-79.

Urban M., Dobrzański A. 2011. Zachwaszczenie plantacji warzyw w warunkach nadmiernego uwilgotnienia gleby. [Weed infestation of vegetable crops in excessive soil moisture condition]. Progress in Plant Protection/Postępy w Ochronie Roślin 51 (1): 369-375. 